\section{Commentary: Management of patients with failing Fontan: More questions than answers}

\author{
Kirk R. Kanter, MD
}

Rajab and Jaggers ${ }^{1}$ review heart transplantation for Fontan failure. Their article raises unresolved questions. When should a Fontan patient be referred for transplantation? Their Table $1^{1}$ outlining indications is disappointingly lacking in concrete guidelines. How does one determine that a Fontan patient has failed all standard therapies? What level of hepatic dysfunction warrants transplantation? To avoid the risk of combined heart/liver transplantation, one must predict when the nearly universal hepatic dysfunction associated with the Fontan circulation will become irreversible.

Despite improved results with heart transplantation in Fontan patients, the challenges of peri-transplant care should not be minimized. These include multiple redo sternotomies, difficulty calculating pulmonary vascular resistance, management of arteriovenous collaterals, bleeding diatheses, need for pulmonary artery reconstruction and rerouting of systemic and/or pulmonary venous connections, preformed antibodies, and underlying debility due to protein-losing enteropathy, hepatic or renal dysfunction, muscle wasting, and so on.

What is the fate of patients who undergo heart transplantation for Fontan failure? Patients transplanted for congenital heart disease do not fare as well as those with idiopathic cardiomyopathy. The median survival for all transplant patients aged 11 to 17 years (most Fontan transplant recipients are teenagers or young adults) is only 14.3 years. ${ }^{2}$ This includes

\footnotetext{
From the Division of Cardio-Thoracic Surgery, Department of Surgery, Emory University School of Medicine, Atlanta, Ga.

Disclosures: The author reported no conflicts of interest.

The Journal policy requires editors and reviewers to disclose conflicts of interest and to decline handling or reviewing manuscripts for which they may have a conflict of interest. The editors and reviewers of this article have no conflicts of interest.

Received for publication May 6, 2020; revisions received May 6, 2020; accepted for publication May 20, 2020; available ahead of print July 2, 2020.

Address for reprints: Kirk R. Kanter, MD, Division of Cardio-Thoracic Surgery, Department of Surgery, Emory University School of Medicine, Children's Healthcare of Atlanta at Egleston, 1405 Clifton Rd, Atlanta, GA 30322 (E-mail: kkanter@ emory.edu).

JTCVS Open 2020;3:160-1

2666-2736

Copyright $(2020$ The Authors. Published by Elsevier Inc. on behalf of The American Association for Thoracic Surgery. This is an open access article under the CC BY-NCND license (http://creativecommons.org/licenses/by-nc-nd/4.0/).

https://doi.org/10.1016/j.xjon.2020.05.008
}

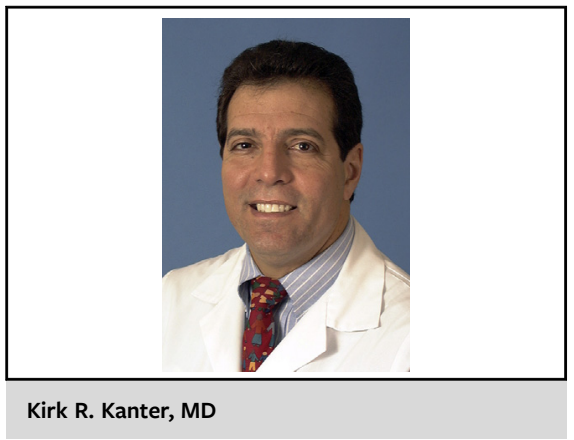

CENTRAL MESSAGE

The care of patients with failing Fontans is difficult. Transplantation is not an ideal solution. A widespread collaborative effort is necessary to answer important questions about this problem.

all transplants, not just patients with congenital heart disease or previous Fontan operations. Certainly, the transplanted Fontan patient cannot be expected to do even this well.

Mechanical circulatory support for Fontan patients is in its infancy, currently used as a bridge to transplant. More than 1000 Fontan procedures are done annually according to the Society of Thoracic Surgeons Congenital Heart Surgery Database. ${ }^{3}$ Yet the number of transplants for patients aged 11 to 17 years has remained constant at 200 to 300 per year (including all idiopathic cardiomyopathy patients and non-Fontan congenital heart disease patients). ${ }^{2}$ Also, congenital heart disease accounts for only $2 \%$ to $3 \%$ of adult transplants. ${ }^{4}$ Due to donor limitations, transplantation cannot be the answer for all patients with failing Fontan, particularly considering Rajab and Jaggers ${ }^{1}$ suggest that nearly all patients with Fontan physiology may require eventual transplantation. Long-term mechanical support of these patients hopefully is the future. Can these patients be supported with a ventricular assist device for the systemic ventricle alone? Is an implantable total artificial heart necessary? Can an intravascular mechanical long-term support device be perfected?

To answer these important questions, a multi-institutional registry of Fontan patients is desirable. Longitudinal followup can aid understanding the onset of Fontan failure, helping ascertain the optimal timing for transplant listing or mechanical assistance. Following these patients after transplantation or mechanical support will define long-term outcomes. Armed with these data, we should improve the fate of 
Fontan patients with a 3-pronged approach: improved medical therapy reducing or delaying the onset of Fontan failure, improved posttransplant management with a goal (possibly unobtainable) of immune tolerance, and the development of reliable and safe long-term implantable mechanical support. The future for patients with failing Fontan might be promising. Remember, there are a lot of Fontan survivors out there!

\section{References}

1. Rajab TK, Jaggers J. Transplantation in Fontan failure: the final stage. J Thorac Cardiovasc Surg Open. 2020;3:154-9.
2. Rossano JW, Singh TP, Cherikh WS, Chambers DC, Harhay MO Hayes D Jr, et al. The International Thoracic Organ Transplant Registry of the International Society for Heart and Lung Transplantation: twenty-second pediatric heart transplantation report-2019; focus theme: donor and recipient size. J Heart Lung Transplant. 2019;38:1028-41.

3. The Society of Thoracic Surgeons (STS) and Duke Clinical Research Institute (DCRI). Data analysis of The Society of Thoracic Surgeons Congenital Heart Surgery Database: January 1, 2015-December 31, 2018. Durham, NC: Duke University Medical Center; August 2019.

4. Khush KK, Cherikh WS, Chambers DC, Harhay MO, Hayes D Jr, Hsich E, et al. The International Thoracic Organ Transplant Registry of the International Society for Heart and Lung Transplantation: thirty-sixth adult heart transplantation report - 2019; focus theme: donor and recipient size match. J Heart Lung Transplant. 2019;38: 1056-66. 